\title{
An ultrasonic assisted direct contact membrane distillation hybrid process for desalination
}

\author{
Deyin Hou $^{\mathrm{a}, *}$, Guohua Dai ${ }^{\mathrm{b}}$, Hua Fan ${ }^{\mathrm{c}}$, Hongjing Huang ${ }^{\mathrm{c}}$, Jun Wang ${ }^{\mathrm{a}, *}$ \\ a State Key Laboratory of Environmental Aquatic Chemistry, Research Center for Eco-Environmental Sciences, Chinese Academy of Sciences, Beijing 100085, \\ PR China \\ ${ }^{\mathrm{b}}$ State Key Laboratory of Vegetation and Environmental Change, Institute of Botany, Chinese Academy of Sciences, Beijing 100093, PR China \\ ' School of Environmental and Chemical Engineering, Nanchang University, Jiangxi 330031, PR China
}

\section{A R T I C L E I N F O}

\section{Article history:}

Received 12 August 2014

Received in revised form

10 November 2014

Accepted 17 November 2014

Available online 22 November 2014

Keywords:

Membrane distillation

Ultrasonic irradiation

Desalination

Permeate flux

Polytetrafluoroethylene

\begin{abstract}
A B S T R A C T
A novel ultrasonic assisted direct contact membrane distillation (USDCMD) hybrid process was designed and the effects of feed temperature, feed concentration, feed velocity, ultrasonic power and frequency on mass transfer were investigated. Under ultrasonic irradiation, changes and damages in membrane structure were found on PVDF membrane, while the pore size and the stretching strain of PP fibers were also enlarged and declined, respectively. The PTFE hollow fiber was selected to carry out USDCMD. The results showed that ultrasonic irradiation could effectively enhance mass transfer. Under the ultrasonic irradiation of $20 \mathrm{kHz}$ and $260 \mathrm{~W}$, the maximum permeate flux enhancement of $60 \%$ was obtained under conditions of feed temperature of $53{ }^{\circ} \mathrm{C}$, feed velocity of $0.25 \mathrm{~m} / \mathrm{s}$ and feed salt concentration of $140 \mathrm{~g} / \mathrm{L}$. The increment was enlarged with the decrease of feed temperature, feed velocity and ultrasonic frequency as well as the increase of feed concentration and ultrasonic power. Ultrasonic irradiation had no significant influence on the mechanical strength, pore size and hydrophobicity of the PTFE membrane in a $240 \mathrm{~h}$ continuous USDCMD experiment, and the novel membrane distillation process exhibited satisfying performance stability, which indicated that ultrasonic irradiation can be applied to membrane distillation for mass transfer enhancement.
\end{abstract}

(c) 2014 Elsevier B.V. All rights reserved.

\section{Introduction}

Membrane distillation (MD) is a thermally driven process suitable for applications in which water is the major component present in the feed solution to be treated [1]. There is a thermally driven vapor transport through non-wetted porous hydrophobic membranes where the driving force is the partial vapor pressure difference across the two sides of membrane pores [2]. In recent years, MD displays a very good application prospect in desalination [3-5]. Compared with conventional desalination processes such as nanofiltration (NF), reverse osmosis (RO) and thermal evaporation, MD can utilize waste heat of low quality, treat wastewater containing higher salt concentration [6-8], and even remove some organics that used to be difficult to remove [9-11]. According to the adopted condensation methods, the MD systems can be classified into four different categories: direct contact membrane distillation (DCMD), air gap membrane distillation (AGMD), sweeping gas membrane distillation (SGMD) and vacuum membrane distillation (VMD) [12]. Among these four MD configurations, the DCMD is the most studied and it is also

\footnotetext{
*Corresponding authors. Tel.: +8610 62849150; fax: +86 1062849150.

E-mail addresses: dyhou@rcees.ac.cn (D. Hou), junwang@rcees.ac.cn (J. Wang).
}

considered to be the simplest in design and application [13]. This is due to the fact that condensation steps carried out inside the membrane module lead to a simple operation mode without the need of external condensers like those in SGMD and VMD.

Although there have been extensive studies on the applicability of MD for water purification applications, the industrial implementation of MD is not yet feasible because of the following four major factors: (1) low permeate flux and mechanical intensity of the hydrophobic membrane, (2) membrane fouling and membrane pore wetting, (3) long term performance instability, and (4) inefficient current MD process systems. Among these considerations, the improvement of membrane permeate flux is believed to be foremost for further commercialization of MD [14]. It is well known that the permeate flux is influenced by the membrane properties, temperature polarization, concentration polarization and channeling effect [15]. Except optimization of membrane materials, development of novel MD devices and effective MD processes is another solution to enhance the permeate flux. Teoh et al. designed different hollow fiber membrane modules with baffles and spacers, it was observed that the permeate flux can be enhanced about 30\% [16]. Phattaranawik et al. [17] also found that the DCMD in spacer-filled channels achieved a higher flux than without spacers and the temperature polarization could be effectively inhibited. Chen et al. [18] incorporated gas bubbling into the DCMD system 
and the gas bubbling not only enhanced the permeate flux but also delayed the occurrence of major flux decline. Li and Sirkar [19] fabricated a rectangular cross-flow membrane module with face box and the cross flow helped to achieve a high permeate flux by reducing the temperature polarization in the feed. To improve hydrodynamics and MD module performance, Yang et al. [20] designed some novel hollow fiber modules with curly fibers, central-tubing for feeding, spacer-wrapped and spacer-knitted fibers.

Ultrasonic wave is referred to the acoustic wave with the frequency between $20 \mathrm{kHz}$ and $10 \mathrm{MHz}$. Several concomitant effects, such as the mechanics, thermotics and cavatition effect, present themselves during the propagation of ultrasonic wave in various media, and these effects have been recognized to be beneficial to many physical and chemical processes [21]. For membrane separation processes, the ultrasonic technique is used mainly in membrane fouling monitoring and control, membrane cleaning and membrane flux enhancement [22-28]. Li et al. and Mairal et al. [29-31] applied the ultrasonic technique as a non-destructive, real-time, in situ measuring technique for the non-invasive direct monitoring of membrane fouling and cleaning during ultrafiltration (UF) and RO, and found that the ultrasonic technique is a useful technique for the non-destructive investigation of fouling and cleaning in membrane applications. Kobayashi et al. [32-36] introduced the ultrasonic technique to create novel anti-fouling membrane processes for membrane water treatments, it was reported that ultrasonic irradiation during membrane filtration was very effective in removing foulants from membranes. Massive evidences exist that the ultrasonic effect is useful for water cleaning of fouled membrane, the ultrasonic cleaning presents advantages and is an effective method compared with other typical cleaning methods using physical and chemical methods [37-39]. In addition, ultrasonic intensity and frequency also increased the permeate flux of membranes [40-42]. Although the ultrasonic irradiation has been successfully applied to some membrane separation systems such as microfiltration (MF), UF and RO, this method has not yet been incorporated into the processes of DCMD.

The subject of this research, the ultrasonic assisted direct contact membrane distillation (USDCMD) hybrid process has not been reported so far. Hence, it is our interest to experimentally investigate the effect of ultrasonic irradiation on DCMD. In this study, online ultrasonic irradiation equipment was incorporated into a DCMD system and batch USDCMD experiments were carried out for desalination with sodium chloride solution as the feed. The influences of feed concentration, flow rate and temperature, ultrasonic irradiation power and frequency on USDCMD performance were investigated comprehensively and systematically. In addition, the effects of ultrasonic irradiation on the hydrophobic hollow fibers were also analyzed via scanning electron microscopy (SEM), capillary flow porometer (CFP) and mechanical strength measurement.

\section{Experimental}

\subsection{Materials and membrane module}

Three different hydrophobic hollow fiber membranes, polytetrafluoroethylene (PTFE), polypropylene (PP) and polyvinylidene fluoride (PVDF) were chosen to fabricate membrane modules. The PTFE and PP hollow fibers were supplied by DD Water Group Co., Ltd. (China) and the Institute of Seawater Desalination and Multipurpose Utilization, SOA (Tianjin, China), respectively. The PVDF hollow fiber membranes were self-prepared by the dry/wet phase inversion process. Hollow fibers in the number of 40 pieces were assembled into a polyester tube (diameter $\left.(\mathrm{mm}) d_{\text {in }} / d_{\text {out }}=15 / 20\right)$ with two UPVC T-tubes and two ends of the bundle of fibers were sealed with solidified epoxy resin to compose a membrane module. The effective membrane length was $100 \mathrm{~mm}$ for each membrane module. The characteristics of the membranes and corresponding modules are presented in Table 1.

\subsection{USDCMD setup}

The USDCMD experimental setup is schematically shown in Fig. 1. The hot salt solution as feed flowed through the shell side of the fibers, while the cold distillate flowed through the lumen side. The initial volumes of the feed and the distillate were $2.0 \mathrm{~L}$ and $0.25 \mathrm{~L}$, respectively. To keep the feed concentration constant, the obtained distillate was reflowed to the feed tank every one hour. Both solutions were circulated in the membrane module with the help of two magnetic pumps (MP-15RN, Shanghai Seisun Pumps, China). The feed and the distillate flowed co-currently through the module, and the circulation feed rate $\left(V_{f}\right)$ was in the range of $0.07-0.25 \mathrm{~m} / \mathrm{s}$, while the

Table 1

The characteristics of the membranes and the membrane modules.

\begin{tabular}{|c|c|c|c|c|c|c|c|}
\hline $\begin{array}{l}\text { Membrane } \\
\text { material }\end{array}$ & Mean pore diameter $(\mu \mathrm{m})$ & $\begin{array}{l}\text { Porosity } \\
(\%)\end{array}$ & $\begin{array}{l}\text { Outer diameter } \\
(\mathrm{mm})\end{array}$ & $\begin{array}{l}\text { Inner diameter } \\
(\mathrm{mm})\end{array}$ & $\begin{array}{l}L E P w \\
\text { (Bar) }\end{array}$ & Contact angle $\left({ }^{\circ}\right)$ & $\begin{array}{l}\text { Effective membrane area } \\
\left(\mathrm{cm}^{2}\right)\end{array}$ \\
\hline PP & 0.28 & 50.76 & 0.40 & 0.20 & 1.32 & 94.8 & 50.2 \\
\hline PVDF & 0.14 & 83.82 & 1.20 & 0.90 & 2.97 & 99.5 & 150.7 \\
\hline PTFE & 0.26 & 45.07 & 1.58 & 0.80 & 1.67 & 129.3 & 198.4 \\
\hline
\end{tabular}

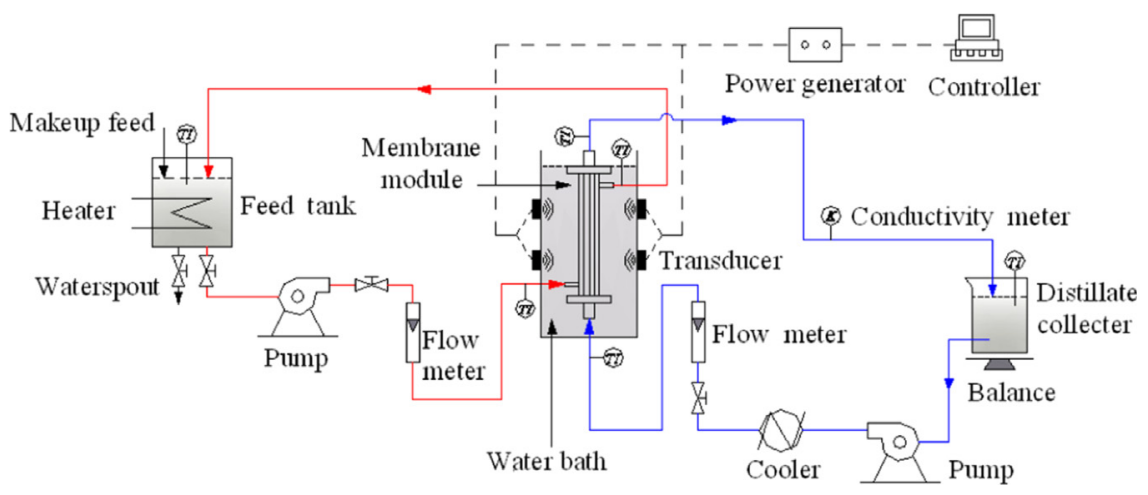

Fig. 1. Schematic diagram of the USDCMD system. 
cold side $\left(V_{p}\right)$ keeping constant at $1.0 \mathrm{~m} / \mathrm{s}$. The feed temperature $\left(T_{\text {f-inlet }}\right)$ was controlled from 40 to $70^{\circ} \mathrm{C}$ by a Pt-100 sensor and a heater connected to an external thermostat (XMTD-2202, Yongshang Instruments, China). The distillate temperature $\left(T_{p \text {-inlet }}\right)$ kept at $20^{\circ} \mathrm{C}$ by a spiral glass heat exchanger immersed in the constant temperature trough of the cooler (SDC-6, Nanjing Xinchen Biotechnology, China). The temperature of both fluids was monitored at the inlet and outlet of the membrane module using four Pt-100 thermoresistances connected to a digital meter (Digit RTD, model XMT-808, Yuyao Changjiang Temperature Meter Instruments, China) with an accuracy of $\pm 0.1^{\circ} \mathrm{C}$. An electric conductivity monitor (CM-230 A, Shijiazhuang Create Instrumentation Technologies, China) was used to monitor the distillate water quality.

In order to study the effect of ultrasonic irradiation, the membrane module was immersed vertically in a water bath $\left(15 \times 15 \times 42 \mathrm{~cm}^{3}\right)$, transducers were adhered to the four outside surfaces of the water bath stainless steel shell. The acoustic power is supplied from a power generator with the power output up to $260 \mathrm{~W}$. Four different resonance frequencies of $20 \mathrm{kHz}, 30 \mathrm{kHz}$, $40 \mathrm{kHz}$ and $68 \mathrm{kHz}$ can be selected for the ultrasonic irradiation. The ultrasonic irradiation device was supplied by Quanyi Electronic Equipment Co., Ltd. (Baoding, China).

\subsection{Analysis methods and instruments}

Membrane characteristics such as porosity, pore size distribution and mechanical properties of the hollow fibers were tested. Morphologies of the membranes before and after ultrasonic irradiation were also observed.

\subsubsection{Membrane porosity test}

The membrane porosity was usually measured by the gravimetric method, determining the weight of liquid contained in the membrane pores. The porosity $\varepsilon$ of the hollow fiber was calculated by the following equation [43]:

$\varepsilon=\frac{\left(w_{1}-w_{2}\right) / D_{L}}{\left(w_{1}-w_{2}\right) / D_{L}+w_{2} / D_{P}}$

where $w_{1}$ is the weight of the wet membrane, $w_{2}$ is the weight of the dry membrane, $D_{P}$ is the polymer density and $D_{L}$ is the liquid density. The liquid used for porosity measurement named Porefil was supported by IB-FT GmbH (Germany) and its surface tension and density were $16 \mathrm{dyn} / \mathrm{cm}$ and $1.87 \mathrm{~g} / \mathrm{ml}$, respectively.

\subsubsection{Pore size distribution and LEPw test}

The pore size distribution of the membrane was investigated by using a Capillary Flow Porometer (Porolux 1000, IB-FT GmbH, Germany). The fibers were fully wetted with the Porefil, and then the measurements were carried out following the procedure described in the literature [1]. The pore size distribution was determined with the aid of the computer software coupled to CFP.

The liquid entry pressure of water ( $L E P w)$ was obtained using the method described by Smolders and Franken [44]. Hollow fibers in the number of 10 pieces were assembled into a test membrane module and the effective hollow fiber length was $50 \mathrm{~mm}$. The container was first filled with $1.0 \mathrm{~L}$ distilled water and then the pressure was applied gradually from the nitrogen cylinder on water at room temperature. The minimum applied pressure at which a continuous flux was observed was the $L E P w$ value. The experiments were carried out three times using different membrane modules made from different batches.

\subsubsection{Membrane morphology analysis}

The morphology of membrane was investigated with a HITACHI S-3000 N scanning electron microscope (SEM) (Hitachi Ltd., Japan). Membrane samples were frozen in liquid nitrogen, fractured to obtain fragments, and sputtered with platinum using a HITACHI E-1010 Ion Sputtering device for SEM observation.

\subsubsection{Membrane contact angle}

The membrane hydrophobicity was determined by gauges of contact angle of droplet with the OCA20 Video-Based Contact Angle Meter (DataPhysics Instruments Ltd., Germany). Water droplets of about $0.3 \mu \mathrm{L}$ were carefully dropped onto the membrane outer surface through a syringe under ambient temperature and the contact angles were obtained by measuring five different positions of each sample.

\subsubsection{Mechanical properties analysis}

Mechanical properties of the fabricated membranes were investigated by measurements with an Instron tensiometer (Instron 5565-5 kN, Instron Corporation, USA). The sample was clamped at both ends and pulled in tension at a constant elongation rate of $10 \mathrm{~mm} / \mathrm{min}$ with an initial length of $20 \mathrm{~cm}$ at room temperature, and five specimens were tested for each hollow fiber sample.

\section{Results and discussions}

\subsection{The hollow fiber membranes selection}

To select a suitable hydrophobic hollow fiber for the USDCMD hybrid process, the influence of ultrasonic irradiation on membrane properties was investigated first. With the feed flow rate set at $0.25 \mathrm{~m} / \mathrm{s}$ and feed temperature at $53{ }^{\circ} \mathrm{C}$, both the DCMD and USDCMD experiments were carried out independently. During the experiments, the sodium chloride concentration in feed was kept constant at $35 \mathrm{~g} / \mathrm{L}$ and the ultrasonic of $20 \mathrm{kHz}$ frequency was used at a fixed power of $260 \mathrm{~W}$.

The experimental results of three hours continuous running are listed in Table 2. The relative permeate flux $J_{R}$ was used to describe the ultrasonic effect on membrane permeability:

$J_{R}=\frac{J_{U S D C M D}}{J_{D C M D}}$

where $J_{U S D C M D}$ is the permeate flux with ultrasonic and $J_{D C M D}$ is the permeate flux without ultrasonic. Although the relative permeate flux of the PVDF membrane was the highest, the permeate conductivity increased continually during the USDCMD process. When the USDCMD experiment ended, the permeate conductivity reached $86.2 \mu \mathrm{S} / \mathrm{cm}$, indicating that the salt solution penetrated through the PVDF hollow fibers. The outer surface SEM images of

Table 2

USDCMD operating conditions and experimental results of the different hollow fiber membranes.

\begin{tabular}{|c|c|c|c|c|c|c|c|c|c|}
\hline \multirow[t]{2}{*}{ Membrane material } & \multirow[t]{2}{*}{$T_{\text {f-inlet }}\left({ }^{\circ} \mathrm{C}\right)$} & \multirow[t]{2}{*}{$T_{\text {f-outlet }}\left({ }^{\circ} \mathrm{C}\right)$} & \multirow[t]{2}{*}{$T_{p \text {-inlet }}\left({ }^{\circ} \mathrm{C}\right)$} & \multirow[t]{2}{*}{$T_{p \text {-outlet }}\left({ }^{\circ} \mathrm{C}\right)$} & \multirow[t]{2}{*}{$J_{R}$} & \multicolumn{2}{|c|}{ Permeate flux $\left(\mathrm{kg} / \mathrm{m}^{2} \mathrm{~h}\right)$} & \multicolumn{2}{|c|}{ Permeate conductivity $(\mu \mathrm{S} / \mathrm{cm})$} \\
\hline & & & & & & DCMD & USDCMD & DCMD & USDCMD \\
\hline PP & 53.3 & 50.2 & 20.0 & 30.2 & 1.67 & 6.36 & 10.61 & 4.5 & 4.7 \\
\hline PVDF & 53.0 & 51.1 & 20.1 & 25.1 & 2.01 & 4.47 & 8.99 & 7.5 & 86.2 \\
\hline PTFE & 53.1 & 51.2 & 20.2 & 23.2 & 1.32 & 1.97 & 2.60 & 4.3 & 4.3 \\
\hline
\end{tabular}



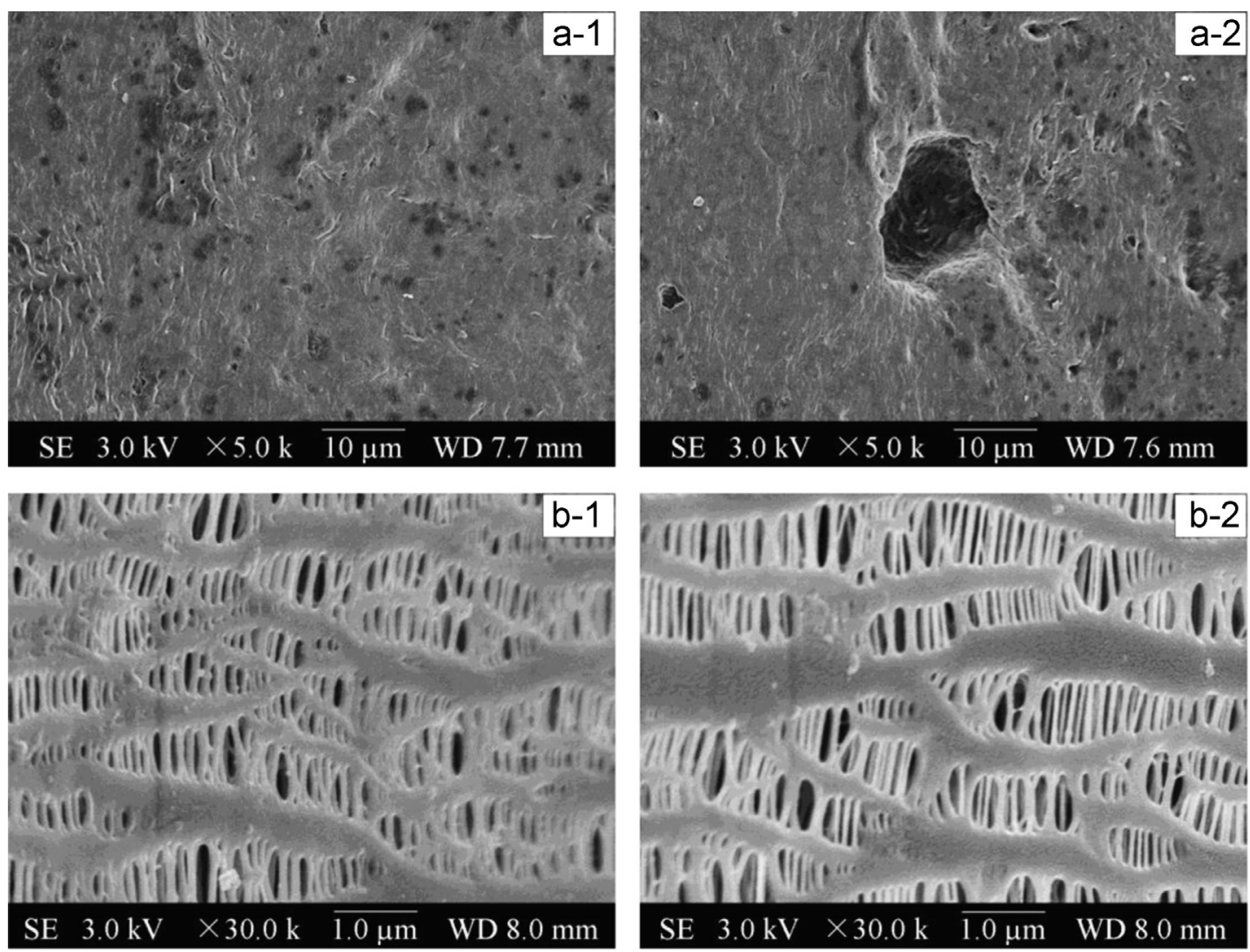

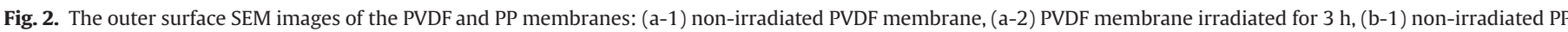
membrane and (b-2) PP membrane irradiated for $3 \mathrm{~h}$.

the PVDF hollow fiber membrane after being used in DCMD and USDCMD are presented in Fig. 2. It can be found that the skin layer was eroded by ultrasonic wave, and some parts were stripped off. The stress-strain curves also demonstrated that ultrasonic irradiation degraded mechanical strength of the PVDF hollow fibers as shown in Fig. 3. The relevant experimental data are listed in Table 3.

The PP and PTFE membranes kept good salt rejection, and the permeate conductivity from these two membranes was below $5.0 \mu \mathrm{S} / \mathrm{cm}$ with ultrasonic irradiation or not. The relative permeate flux of the PP membrane was higher than that from PTFE membrane as listed in Table 2, but the three hours ultrasonic irradiation reduced the stretching strain from $190 \%$ to $163 \%$ for PP hollow fiber. It was found that there was no obvious difference between the outer surface SEM images of the PP membranes before and after ultrasound irradiation. However, the pore size distribution test showed that the ultrasonic irradiation enlarged the membrane pore diameter as shown in Fig. 4. After three hours ultrasonic irradiation, the bubble point pore size and the mean pore size of the PP fiber were increased to $2.40 \mu \mathrm{m}$ and $0.32 \mu \mathrm{m}$, respectively. For PTFE hollow fiber membrane, the performance stability, mechanical properties and pore size distribution were hardly influenced by ultrasonic irradiation, which indicated that the PTFE membrane should be the optimal membrane material to be utilized in the USDCMD hybrid process for desalination. Therefore, the PTFE hollow fiber membrane was selected to be used in the following USDCMD experimental research.

\subsection{The influence of feed temperature on USDCMD}

MD is a thermally driven process and the temperature determines the vapor pressure of feed solution. The influence of feed temperature on the USDCMD hybrid process was investigated first. With the feed velocity set at $0.25 \mathrm{~m} / \mathrm{s}$ and the feed salt concentration at $35 \mathrm{~g} / \mathrm{L}$, both
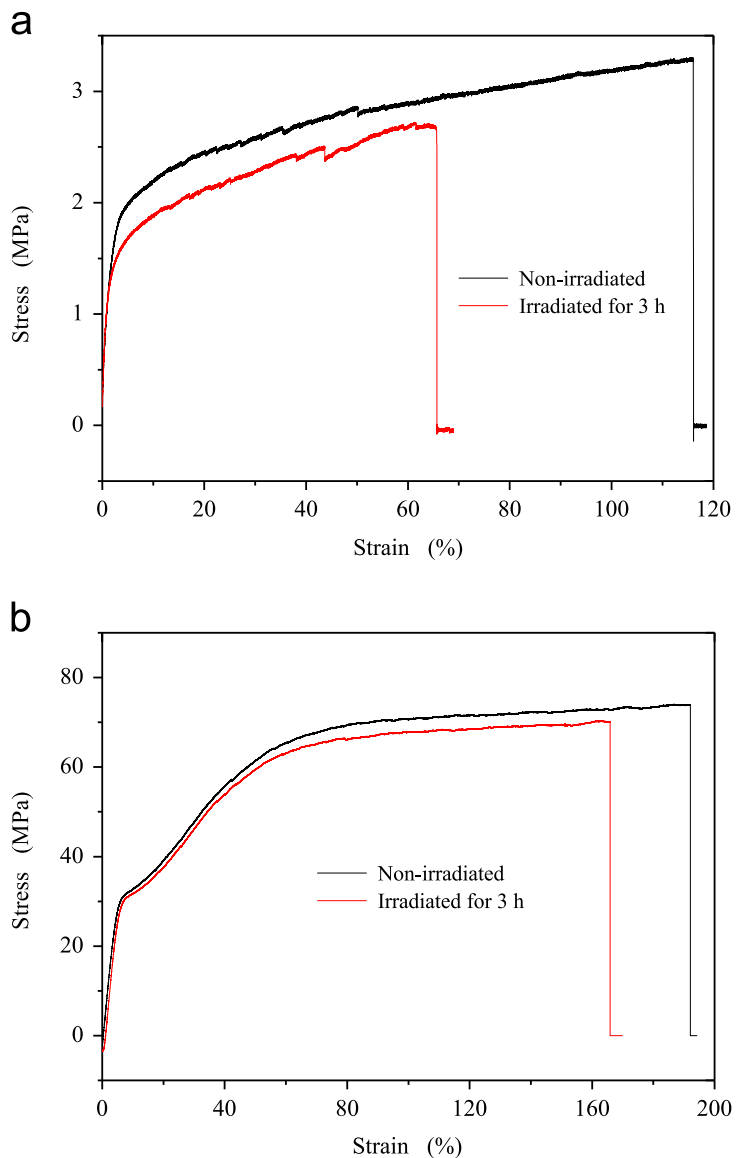

Fig. 3. Stress-strain curves of the hollow fiber membranes: (a) PVDF membranes and (b) PP membranes. 
Table 3

Mechanical properties of the hollow fiber membranes.

\begin{tabular}{llclc}
\hline $\begin{array}{l}\text { Membrane } \\
\text { material }\end{array}$ & $\begin{array}{l}\text { Ultrasonic } \\
\text { irradiation }\end{array}$ & $\begin{array}{l}\text { Load at } \\
\text { break (N) }\end{array}$ & $\begin{array}{l}\text { Stretching strain at } \\
\text { break (\%) }\end{array}$ & $\begin{array}{l}\text { Stress at } \\
\text { break (MPa) }\end{array}$ \\
\hline PP & N & 6.98 & 190.35 & 74.02 \\
& Y & 6.63 & 163.81 & 70.31 \\
PVDF & N & 1.63 & 114.18 & 3.30 \\
& Y & 1.35 & 64.77 & 2.72 \\
PTFE & N & 109.53 & 88.49 & 75.79 \\
& Y & 109.49 & 87.67 & 75.76 \\
\hline
\end{tabular}

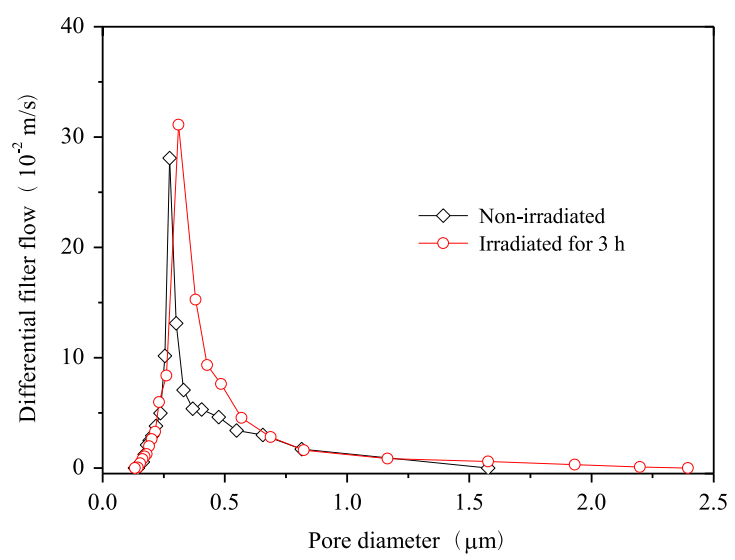

Fig. 4. Pore size distribution of the PP hollow fiber membranes.

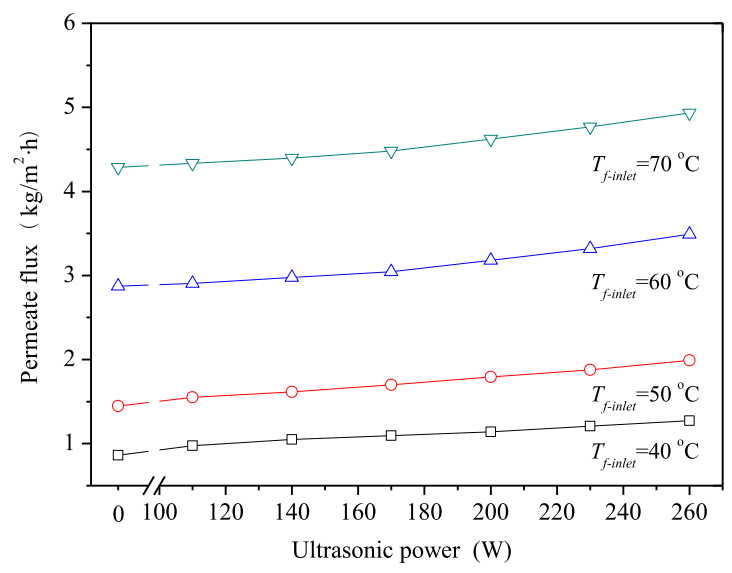

Fig. 5. The influence of feed temperature on permeate flux.

DCMD and USDCMD desalination experiments were carried out at four different temperature levels. For the USDCMD hybrid process, the ultrasonic frequency was fixed at $20 \mathrm{kHz}$ and the ultrasonic power varied in the range of $110-260 \mathrm{~W}$. The permeate conductivity was below $4.5 \mu \mathrm{S} / \mathrm{cm}$ for all the cases tested. The obtained permeate flux with different feed temperatures is shown in Fig. 5.

It can be seen that ultrasonic irradiation really increased the permeate flux. The stronger the ultrasonic irradiation power, the higher the permeate flux yield. It is also found that with the same ultrasonic irradiation power, a higher feed temperature led to a higher permeate flux. As shown in Fig. 6, despite the increasing trend in the absolute amount of permeate flux by ultrasonic irradiation, the relative permeate flux declined with the increase of feed temperature. In the investigated range, the enhancement of permeate flux by the ultrasonic irradiation can reach as high as $47 \%$.

According to the Antoine equation [45], there is an exponential relationship between the vapor pressure difference and temperature. With the feed temperature increase, the permeate flux was enhanced.

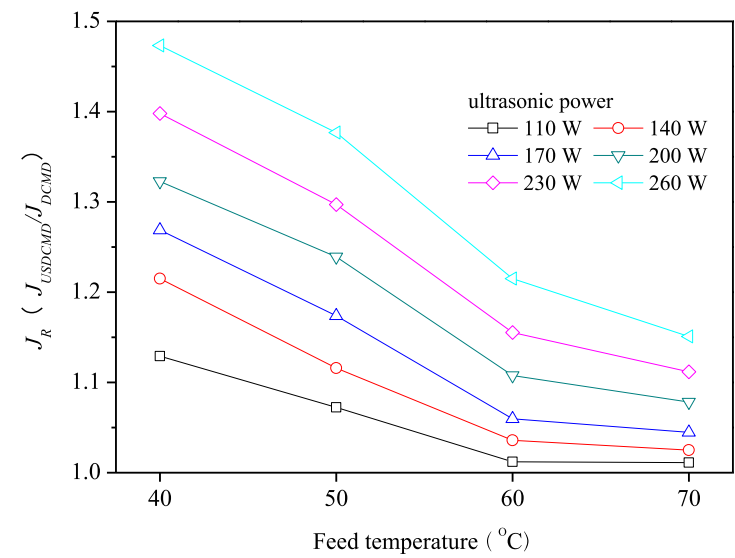

Fig. 6. The influence of feed temperature on ultrasonic enhancement of permeate flux.

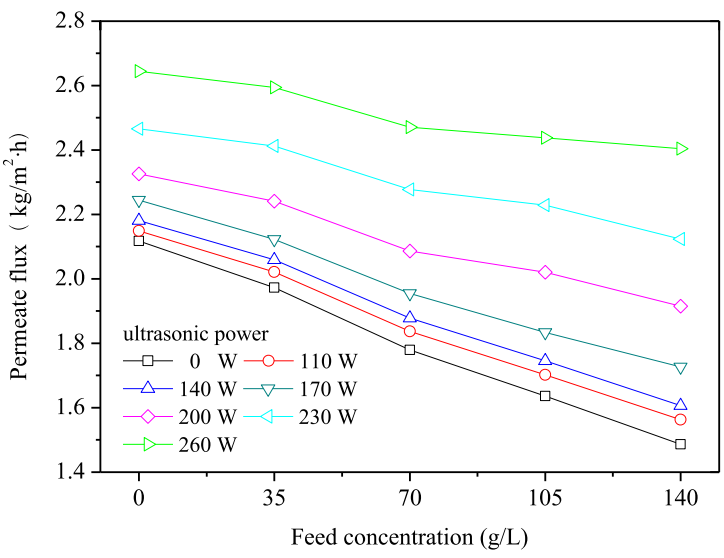

Fig. 7. The influence of feed concentration on permeate flux.

When the feed temperature was at a lower level such as $40{ }^{\circ} \mathrm{C}$, the relative permeate flux was much higher than that from the higher feed temperature, which meant that the ultrasonic irradiation was more efficient in the enhancement of permeate flux for the DCMD process with low feed temperature. The feed viscosity and the boundary layer thickness would decline with the feed temperature increasing, which was favorable to enhance mass transfer coefficient. In this case, the effect of ultrasonic irradiation on permeate flux enhancement was reduced. The bulk feed temperature increased slightly with the increase of ultrasonic irradiation power, while the membrane surface temperature would improve significantly as the ultrasonic irradiation intensified, which had been demonstrated by Zhu and Liu [46]. Therefore, as ultrasonic irradiation power increase, the difference between the bulk temperature and the membrane surface temperature reduced, leading to a reduction of temperature polarization. As a result, the relative permeate flux increased with the ultrasonic irradiation power increasing.

\subsection{The influence of feed concentration on USDCMD}

Fixing feed velocity at $0.25 \mathrm{~m} / \mathrm{s}$ and feed temperature at $53^{\circ} \mathrm{C}$, DCMD experiments were conducted with and without irradiation under several kinds of ultrasonic power, and the ultrasonic frequency was set at $20 \mathrm{kHz}$. The influence of feed concentration on permeate flux is presented in Fig. 7. It can be found that the permeate flux declined with the feed concentration increase no matter whether in the presence of ultrasonic irradiation or not, but the ultrasonic irradiation mitigated permeate flux attenuation as feed concentration increasing. The stronger the ultrasonic irradiation power, the less the permeate flux drop. During these experiments, it was observed that 
the permeate conductivity was kept less than $4.5 \mu \mathrm{S} / \mathrm{cm}$ without affecting by feed concentration.

The increase of salt concentration in the feed would reduce the partial vapor pressure and consequently reduces the driving force of the MD process. With the feed concentration increasing, both the feed viscosity and the boundary layer thickness increased, which aggravated concentration polarization on the feed membrane surface, so there was also the contribution due to the effect of the concentration polarization for the permeate flux decline. Although the absolute permeate flux decreased with feed concentration increasing, the relative permeate flux was improved. The influence of feed concentration on the relative permeate flux is shown in Fig. 8. Ultrasonic wave can bring significant mechanical and thermal effects and generate powerful shock wave and microstreaming with high speed. The mechanical effect promoted turbulence, reduced the boundary layer and intensified eddy diffusion. The microstreaming, shock wave and acoustic streaming can continuously stimulate the liquid-membrane interface, thus refreshed the interface and prevented membrane fouling. All of these were beneficial to relieve the negative effect of feed concentration increase on the mass transfer of the DCMD process. The higher the feed concentration was, the more obvious the ultrasonic enhancement of permeate flux could be observed.

\subsection{The influence of feed velocity on USDCMD}

The feed velocity determines the residence time of feed solution in ultrasonic field. In addition, the feed velocity also influences flow state, mass transfer and heat transfer in the MD process. Therefore, the effect of the feed flow rate was investigated in the range of

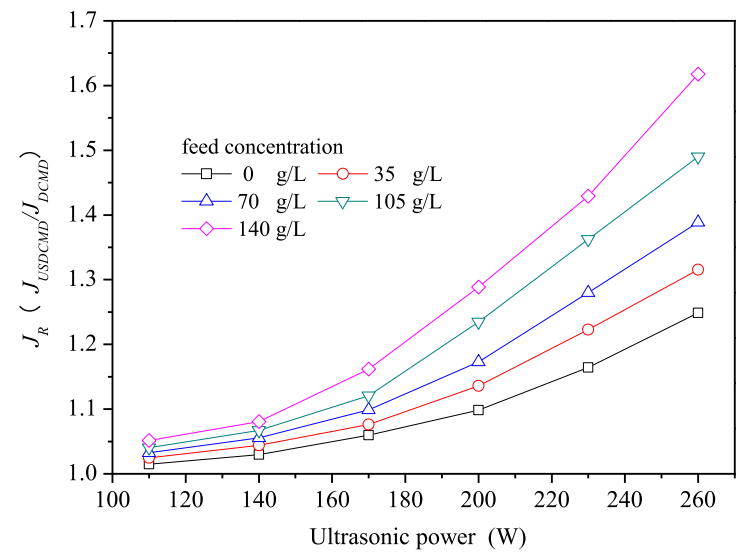

Fig. 8. The influence of feed concentration on ultrasonic enhancement of permeate flux.

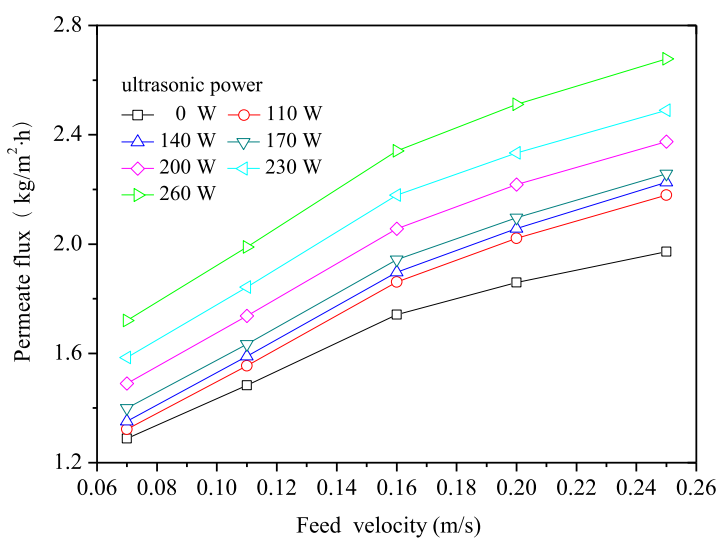

Fig. 9. The influence of feed velocity on permeate flux.
0.07-0.25 m/s, whereas the feed concentration and feed temperature were kept constant at $35 \mathrm{~g} / \mathrm{L}$ and $53^{\circ} \mathrm{C}$, respectively. The ultrasonic frequency was fixed at $20 \mathrm{kHz}$ and the ultrasonic power varied in the range of $0-260 \mathrm{~W}$. The influence of feed flow rate on the permeate flux is shown in Fig. 9.

It is shown that the permeate flux increased with an increase of the feed flow rate. The increase in feed flow rate could weaken the temperature and concentration polarization effects, raise the heat and mass transfers coefficients. As a result, both the permeate flux and heat transport across the hydrophobic membrane would be improved. Ultrasonic irradiation was helpful to the permeate flux enhancement for all the feed velocity levels, and the higher ultrasonic power led to the larger permeate flux enhancement at the same feed flow rate. The effect of feed flow rate on the relative permeate flux is illustrated in Fig. 10. It can be found that the effect of ultrasonic irradiation on permeate flux enhancement at lower feed velocity was more obvious compared with that at higher feed flow rate. With feed velocity increasing, the relieving effect of temperature polarization and concentration polarization from ultrasonic irradiation became less, then the growth of the relative permeate flux would be slower. The relative permeate flux increased remarkably with the ultrasonic power increase, which may be partly attributed to the low feed flow rate. In the range of $0.07-0.25 \mathrm{~m} / \mathrm{s}$, the feed flow was primarily laminar (the Reynolds number, $R e \ll 2000$ ), and the effect of ultrasonic irradiation on permeate flux enhancement would be more distinct with the ultrasonic power increasing.

\subsection{The influence of ultrasonic power and frequency on USDCMD}

Besides ultrasonic power, ultrasonic frequency also plays an important role in the USDCMD hybrid process. In the present work,

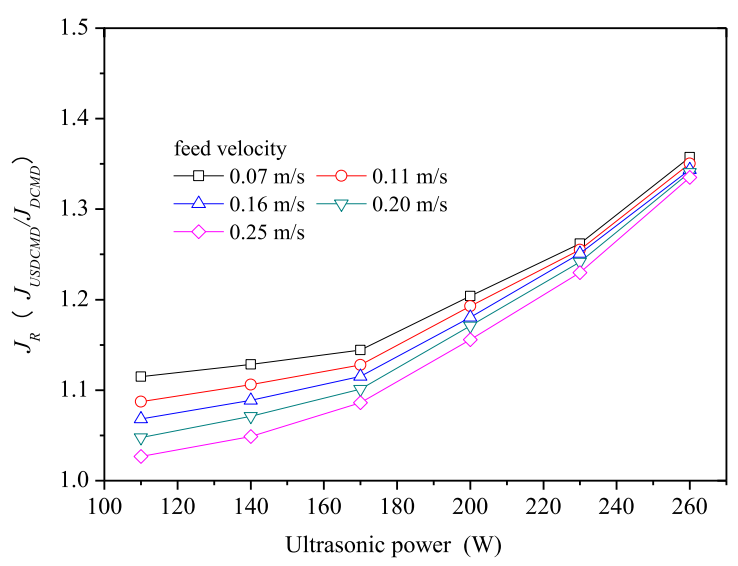

Fig. 10. The influence of feed velocity on ultrasonic enhancement of permeate flux

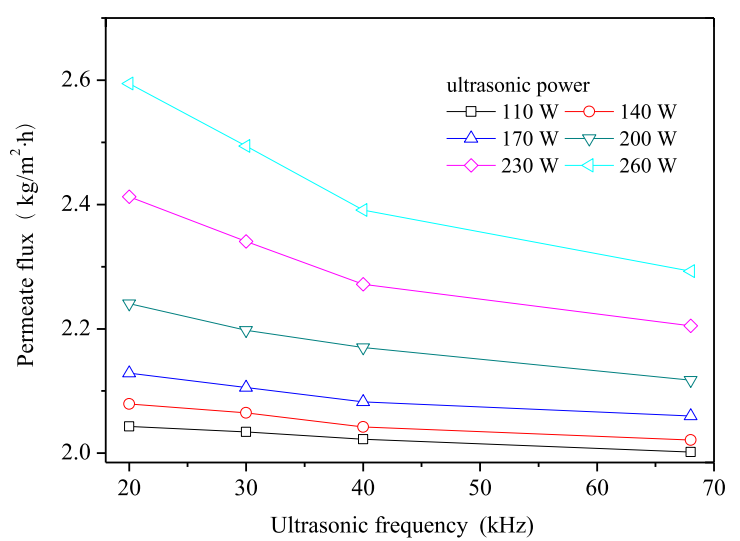

Fig. 11. The influence of ultrasonic power and frequency on permeate flux. 
ultrasonic irradiation effect at frequencies of $20,30,40$ and $68 \mathrm{kHz}$ was investigated with the ultrasonic power in the range of 110$260 \mathrm{~W}$. During the experiments, the feed velocity was fixed at $0.25 \mathrm{~m} / \mathrm{s}$, and the feed concentration and feed temperature were kept constant at $35 \mathrm{~g} / \mathrm{L}$ and $53{ }^{\circ} \mathrm{C}$, respectively. The effect of ultrasonic irradiation on the absolute permeate flux and relative permeate flux are shown in Figs. 11 and 12, respectively.

It can be found that ultrasonic irradiation with higher power and at lower frequency was more favorable to improve permeate flux, which agreed with the results of ultrasonic irradiation on permeate flux enhancement in microfiltration and ultrafiltration [32]. In general, an increase in ultrasonic power strengthens cavitation effects. Under the same ultrasonic power, an increase of ultrasonic frequency reduces the production and intensity of cavitation in liquid. In the ultrasonic filed

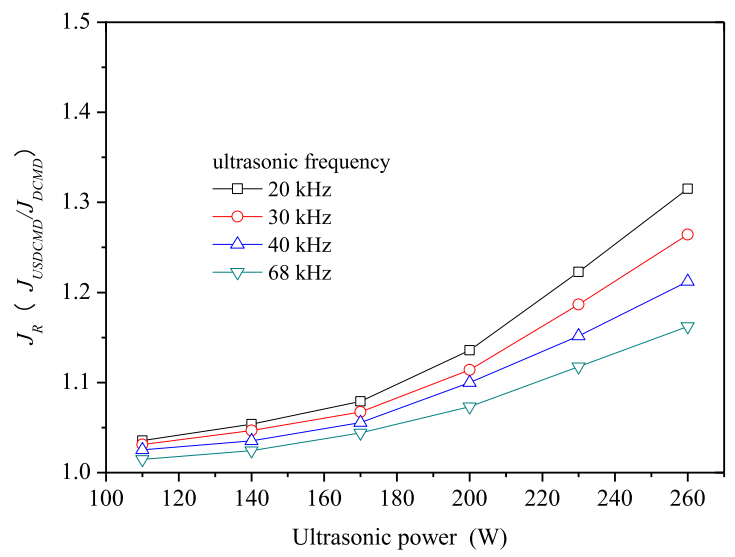

Fig. 12. The influence of ultrasonic power and frequency on ultrasonic enhancement of permeate flux.

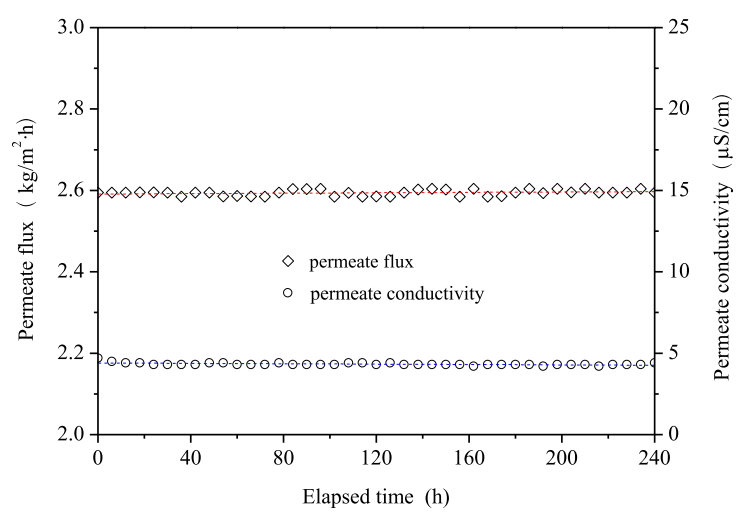

Fig. 13. Variation of membrane permeability along with operating time.

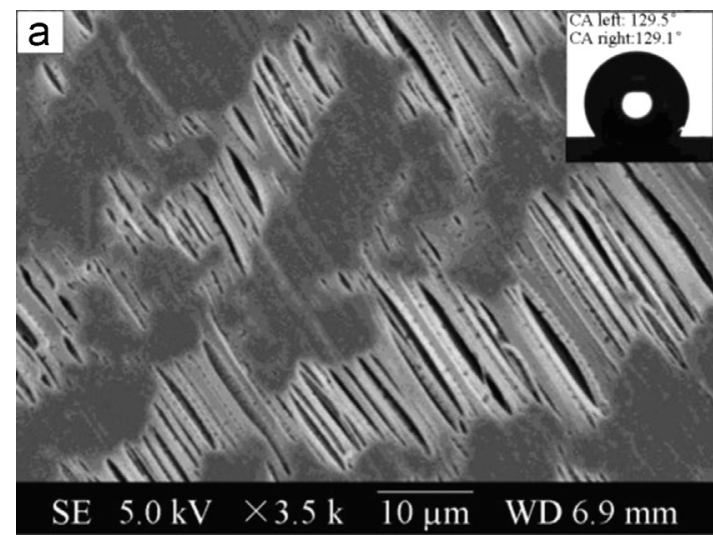

with higher power and lower frequency, the remarkable cavitation phenomena occurred in the water bath in which the PTFE hollow fibers were immersed. Cavitation is usually considered to play the pivotal role in the ultrasonic enhancement of membrane separation process. The formation, growth, compression, and sudden collapse of cavitation bubbles in liquids produce mechanical and thermal effects, which can enhance the efficiency of mass transfer. For the $20 \mathrm{kHz}$ frequency and $260 \mathrm{~W}$ power case, the enhancement of permeate flux can get as high as $32 \%$, while the value of permeate flux enhancement was only $1.5 \%$ for the USDCMD process with $68 \mathrm{kHz}$ frequency and $110 \mathrm{~W}$ power ultrasonic irradiation. Therefore, for the USDCMD hybrid process, low frequency and high power ultrasonic irradiation appear to be effective in permeate flux enhancement.

\subsection{USDCMD performance stability analysis}

From an industrial application perspective, it is important to maintain the membrane permeability, keeping the permeate flux and solute rejection during the MD desalination process. To investigate the performance stability of the USDCMD hybrid process, a $240 \mathrm{~h}$ continuous desalination experiment of aqueous sodium chloride solution was conducted with ultrasonic power at $260 \mathrm{~W}$ and frequency at $20 \mathrm{kHz}$. The feed temperature and flow rate were fixed at $53{ }^{\circ} \mathrm{C}$ and $0.25 \mathrm{~m} / \mathrm{s}$, respectively. The feed $\mathrm{NaCl}$ concentration was kept at $35 \mathrm{~g} / \mathrm{L}$ and other operating parameters were in accordance with the previous experiments. The result of desalination performance is presented in Fig. 13.

It can be observed that the permeate flux was stable at about $2.60 \mathrm{~kg} / \mathrm{m}^{2} \mathrm{~h}$ and the permeate conductivity maintained in the range of $4.3-4.7 \mu \mathrm{S} / \mathrm{cm}$ during the whole experimental process, the PTFE hollow fiber exhibited satisfying performance stability. The SEM images of the PTFE membrane are presented in Fig. 14. It was found that there was no obvious difference between the outer surface SEM images of the PTFE membranes before and after being used in the USDCMD process. The contact angle of the membrane stabilized at $129.6 \pm 0.5^{\circ}$, suggesting that the membrane hydrophobicity was not influenced by ultrasonic irradiation. The pore size distribution and mechanical properties of the PTFE membrane can be found in Figs. 15 and 16 , respectively. The mean pore diameter was $0.26 \mu \mathrm{m}$ and the largest pore diameter was $1.27 \mu \mathrm{m}$, the $240 \mathrm{~h}$ ultrasonic irradiation could not reduce or enlarge the membrane pores. In Fig. 16, it can be clearly seen that the stress-strain curves of the PTFE membranes before and after being exposed in ultrasonic field almost coincide with each other. All of these demonstrated that the PTFE hollow fiber was suitable for the USDCMD hybrid process.

It is necessary to note that the ultrasonic irradiation will bring the possible risk of degradation or modification of the compounds contained in the feed to be treated. For this reason, more careful

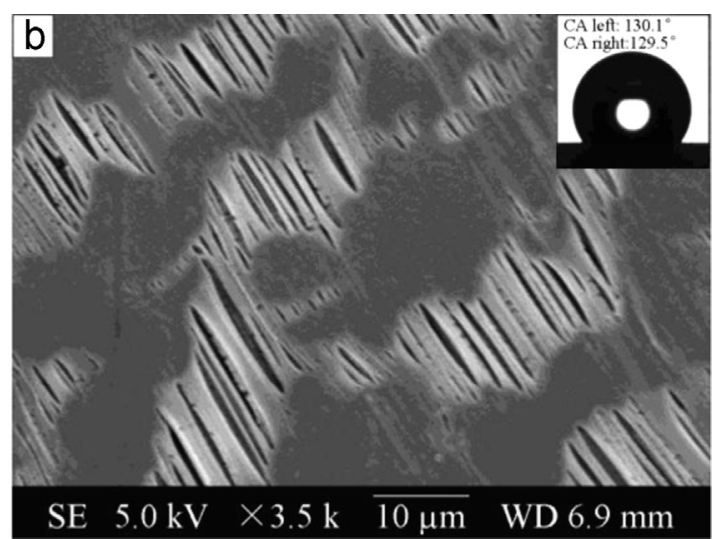

Fig. 14. The SEM image and contact angle of the PTFE membrane outersurface: (a) non-irradiated PTFE membrane and (b) PTFE membrane irradiated for 240 h. 
a

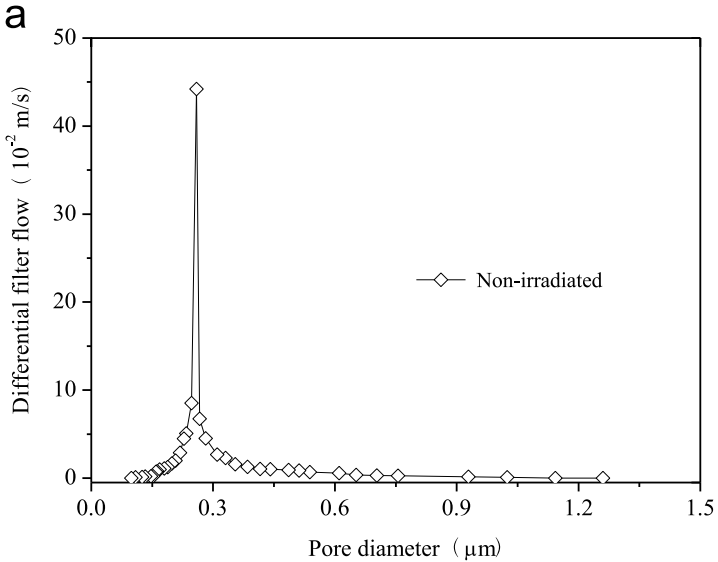

b

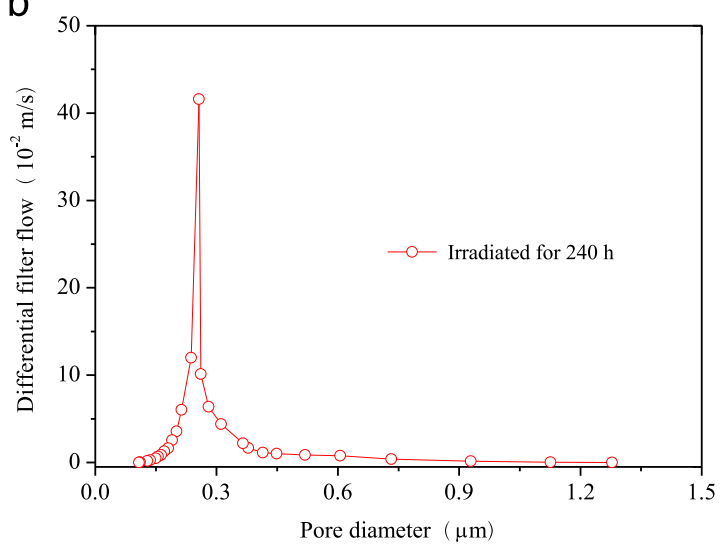

Fig. 15. Pore size distribution of the PTFE hollow fiber membranes.

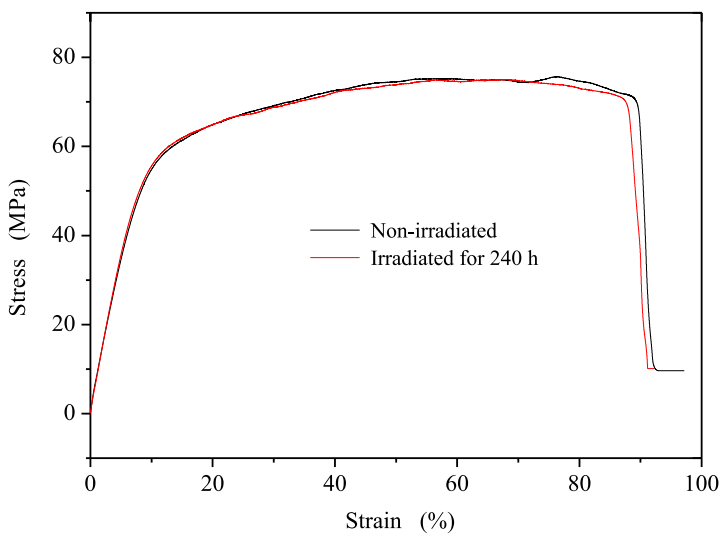

Fig. 16. Stress-strain curves of the PTFE hollow fiber membrane.

evaluations are needed whether the USDCMD hybrid process can be applied in some specific fields such as food processing, blood and protein purification, and extraction of some organic compounds from dilute aqueous solutions. However, it is believed that if the USDCMD hybrid process attempted in this work is accompanied with higher permeate flux PTFE membrane and more efficient process design, the novel USDCMD process may be of great potential to be utilized in desalination.

\section{Conclusions}

In the present work, a novel membrane distillation process, ultrasonic assisted direct contact membrane distillation (USDCMD) hybrid process, was designed. The effects of feed temperature, feed concentration, feed velocity, ultrasonic power and frequency on ultrasonic irradiation enhancement of the mass transfer of DCMD were preliminarily investigated.

Under ultrasonic irradiation, changes and damages in membrane structure were found on PVDF hollow fiber. The ultrasonic irradiation eroded PVDF membrane skin layer, even led to the formation of holes, damaged the membrane mechanical strength. As a result, the capability of solute rejection was destroyed. Although there was no great change in the PP membrane morphology under ultrasonic irradiation, the membrane pore size was enlarged and the stretching strain of the PP fibers declined about 15\%. The PTFE hollow fiber could maintain its properties and was hardly influenced by ultrasonic irradiation. Thus, the PTFE membrane was selected to be applied in the USDCMD hybrid process.

Ultrasonic irradiation could enhance the mass transfer of DCMD. The remarkable effect of ultrasonic irradiation on permeate flux enhancement was obtained at lower feed velocity, feed temperature and higher feed concentration. The application of ultrasonic irradiation could lead to a permeate flux enhancement as high as $60 \%$ without destroying the rejection of solute. It was also found that ultrasonic irradiation with $20 \mathrm{kHz}$ frequency could improve permeate flux more efficiently compared with that of $68 \mathrm{kHz}$, and the permeate flux increased with the ultrasonic power increasing at the same ultrasonic frequency.

Ultrasonic irradiation influenced little on the mechanical strength, pore size distribution and hydrophobicity of the PTFE membrane in a $240 \mathrm{~h}$ USDCMD experiment, and the novel hybrid membrane distillation process exhibited satisfying performance stability. All the results demonstrated that ultrasonic irradiation can be applied to membrane distillation for the enhancement of mass transfer, and the USDCMD hybrid process with PTFE hollow fibers can be conducted continuously.

\section{Acknowledgments}

Financial support provided by the National Natural Science Foundation of China (Nos. 51138008 and 51108445) and the special fund from the State Key Laboratory of Environmental Aquatic Chemistry (No. 13Z04ESPCT) are gratefully acknowledged.

\begin{tabular}{|c|c|}
\hline \multicolumn{2}{|c|}{ Nomenclature } \\
\hline MD & membrane desalination \\
\hline DCMD & direct contact membrane desalination \\
\hline USDCML & $\begin{array}{l}\text { ultrasonic assisted direct contact membrane } \\
\text { distillation }\end{array}$ \\
\hline SEM & scanning electron microscopy \\
\hline CFP & capillary flow porometer \\
\hline $\mathrm{PP}$ & polypropylene \\
\hline PVDF & polyvinylidene fluoride \\
\hline PTFE & polytetrafluoroethylene \\
\hline$L E P W$ & liquid entry pressure of water (Bar) \\
\hline$J_{R}$ & relative permeate flux (dimensionless) \\
\hline$J_{U S D C M D}$ & permeate flux in USDCMD $\left(\mathrm{kg} / \mathrm{m}^{2} \mathrm{~h}\right)$ \\
\hline$J_{D C M D}$ & permeate flux in DCMD $\left(\mathrm{kg} / \mathrm{m}^{2} \mathrm{~h}\right)$ \\
\hline$T_{\text {f-inlet }}$ & feed temperature in membrane module inlet $\left({ }^{\circ} \mathrm{C}\right)$ \\
\hline$T_{f-o u t l e}$ & feed temperature in membrane module outlet $\left({ }^{\circ} \mathrm{C}\right)$ \\
\hline$T_{p-i n l e t}$ & $\begin{array}{l}\text { distillate temperature in membrane module inlet } \\
\left({ }^{\circ} \mathrm{C}\right)\end{array}$ \\
\hline$T_{\text {p-outlet }}$ & $\begin{array}{l}\text { distillate temperature in membrane module outlet } \\
\left({ }^{\circ} \mathrm{C}\right)\end{array}$ \\
\hline$V_{f}$ & feed flow rate $(\mathrm{m} / \mathrm{s})$ \\
\hline
\end{tabular}




$\begin{array}{ll}V_{p} & \text { distillate flow rate }(\mathrm{m} / \mathrm{s}) \\ \varepsilon & \text { membrane porosity }(\%) \\ w_{1} & \text { wet membrane weight }(\mathrm{g}) \\ w_{2} & \text { dry membrane weight }(\mathrm{g}) \\ D_{P} & \text { polymer density }(\mathrm{g} / \mathrm{ml}) \\ D_{L} & \text { the density of liquid used for } \varepsilon \text { test }(1.87 \mathrm{~g} / \mathrm{ml})\end{array}$

\section{References}

[1] K.Y. Wang, T.S. Chung, M. Gryta, Hydrophobic PVDF hollow fiber membranes with narrow pore size distribution and ultra-thin skin for the fresh water production through membrane distillation, Chem. Eng. Sci. 63 (2008) 2587-2589.

[2] M. Qtaishat, M. Khayet, T. Matsuura, Guidelines for preparation of higher flux hydrophobic/hydrophilic composite membranes for membrane distillation, J. Membr. Sci. 329 (2009) 193-200.

[3] S. Chung, C.D. Seo, H. Lee, J.H. Choi, J. Chung, Design strategy for networking membrane module and heat exchanger for direct contact membrane distillation process in seawater desalination, Desalination 349 (2014) 126-135.

[4] A. Chafidz, S. Al-Zahrani, M.N. Al-Otaibi, C.F. Hoong, T.F. Lai, M. Prabu, Portable and integrated solar-driven desalination system usingmembrane distillation for arid remote areas in Saudi Arabia, Desalination 345 (2014) 36-49.

[5] D. Winter, J. Koschikowski, S. Ripperger, Desalination using membrane distillation: flux enhancement by feed water deaeration on spiral-wound modules, J. Membr. Sci. 423-424 (2012) 215-224.

[6] C.M. Tun, A.G. Fane, J.T. Matheickal, R. Sheikholeslami, Membrane distillation crystallization of concentrated salts-flux and crystal formation, J. Membr. Sci. 257 (2005) 144-155.

[7] C.R. Martinetti, A.E. Childress, T.Y. Cath, High recovery of concentrated RO brines using forward osmosis and membrane distillation, J. Membr. Sci. 331 (2009) 31-39.

[8] E. Curcio, X. Ji, G. Di Profio, A.O. Sulaiman, E. Fontananova, E. Drioli, Membrane distillation operated at high seawater concentration factors: role of the membrane on $\mathrm{CaCO}_{3}$ scaling in presence of humic acid, J. Membr. Sci. 346 (2010) 263-269.

[9] B. Wu, X. Tan, K. Li, W.K. Teo, Removal of 1,1,1-trichloroethane from water using a polyvinylidene fluoride hollow fiber membrane module: vacuum membrane distillation operation, Sep. Purif. Technol. 52 (2006) 301-309.

[10] K.C. Wijekoon, F.I. Hai, J. Kang, W.E. Price, T.Y. Cath, L.D. Nghiem, Rejection and fate of trace organic compounds (TrOCs) during membrane distillation, J Membr. Sci. 453 (2014) 636-642.

[11] G. Lewandowicz, W. Bialas, B. Marczewski, D. Szymanowska, Application of membrane distillation for ethanol recovery during fuel ethanol production, J. Membr. Sci. 375 (2011) 212-219.

[12] C.K. Chiam, R. Sarbatly, Vacuum membrane distillation processes for aqueous solution treatment-a review, Chem. Eng. Process. 74 (2013) 27-54.

[13] M.S. El-Bourawi, Z.W. Ding, R.Y. Ma, M. Khayet, A framework for better understanding membrane distillation separation process, J. Membr. Sci. 285 (2006) 4-29.

[14] M.M. Teoh, T.S. Chung, Membrane distillation with hydrophobic macrovoid-free PVDF-PTFE hollow fiber membranes, Sep. Purif. Technol. 66 (2009) 229-236.

[15] X. Yang, R. Wang, L. Shi, A.G. Fane, M. Debowski, Performance improvement of PVDF hollow fiber-based membrane distillation process, J. Membr. Sci. 369 (2011) 437-447.

[16] M.M. Teoh, S. Bonyadi, T.S. Chung, Investigation of different hollow fiber module designs for flux enhancement in the membrane distillation process, J. Membr. Sci. 311 (2008) 371-379.

[17] J. Phattaranawik, R. Jiraratananon, A.G. Fane, C. Halim, Mass flux enhancement using spacer filled channels in direct contact membrane distillation, J. Membr. Sci. 187 (2001) 193-201.

[18] G.Z. Chen, X. Yang, R. Wang, A.G. Fane, Performance enhancement and scaling control with gas bubbling in direct contact membrane distillation, Desalination 308 (2013) 47-55.

[19] B.A. Li, K.K. Sirkar, Novel membrane and device for direct contact membrane distillation-based desalination process, Ind. Eng. Chem. Res. 43 (2004) 5300-5309.

[20] X. Yang, H. Yu, R. Wang, A.G. Fane, Optimization of microstructured hollow fiber design for membrane distillation applications using CFD modeling, J Membr. Sci. 421-422 (2012) 258-270.

[21] L.Y. Liu, Z.W. Ding, L.J. Chang, R.Y. Ma, Z.R. Yang, Ultrasonic enhancement of membrane-based deoxygenation and simultaneous influence on polymeric hollow fiber membrane, Sep. Purif. Technol. 56 (2007) 133-142.
[22] C. Zhua, G.L. Liu, C.S. Cheung, C.W. Leung, Z.C. Zhu, Ultrasonic stimulation on enhancement of air gap membrane distillation, J. Membr Sci. 161 (1999) 85-93.

[23] J.H. Chen, Y.C. Yang, J.Y. Huang, On-line monitoring and diagnosis of membrane fouling using ultrasonic techniques, Chemom. Intell. Lab. Syst. 127 (2013) 147-157.

[24] R. Sanderson, J.X. Li, L.J. Koen, L. Lorenzen, Ultrasonic time-domain reflectometry as a non-destructive instrumental visualization technique to monitor inorganic fouling and cleaning on reverse osmosis membranes, J. Membr. Sci. 207 (2002) 105-117.

[25] J.X. Li, R.D. Sanderson, E.P. Jacobs, Ultrasonic cleaning of nylon microfiltration membranes fouled by Kraft paper mill effluent, J. Membr. Sci. 205 (2002) 247-257.

[26] D. Chen, L.K. Weavers, H.W. Walker, J.J. Lenhart, Ultrasonic control of ceramic membrane fouling caused by natural organic matter and silica particles, J. Membr. Sci. 276 (2006) 135-144.

[27] A. Mirzaie, T. Mohammadi, Effect of ultrasonic waves on flux enhancement in microfiltration of milk, J. Food Eng. 108 (2012) 77-86.

[28] M. Cai, S.N. Zhao, H.H. Liang, Mechanisms for the enhancement of ultrafiltration and membrane cleaning by different ultrasonic frequencies, Desalination 263 (2010) 133-138.

[29] X.H. Li, J.X. Li, J. Wang, H. Wang, B.Q. He, H.W. Zhang, W.S. Guo, H.H. Ngo, Experimental investigation of local flux distribution and fouling behavior in double-end and dead-end submerged hollow fiber membrane modules, J. Membr. Sci. 453 (2014) 18-26.

[30] A.P. Mairal, A.R. Greenberg, W.B. Krantz, Investigation of membrane fouling and cleaning using ultrasonic time-domain reflectometry, Desalination 130 (2000) 45-60.

[31] J.X. Li, R.D. Sanderson, In situ measurement of particle deposition and its removal in microfiltration by ultrasonic time-domain reflectometry, Desalination 146 (2002) 169-175.

[32] T. Kobayashi, T. Kobayashi, Y. Hosaka, N. Fujii, Ultrasound-enhanced membrane-cleaning processes applied water treatments: influence of sonic frequency on filtration treatments, Ultrasonics 41 (2003) 185-190.

[33] S. Muthukumaran, S. Kentish, S. Lalchandani, M. Ashokkumar, R. Mawson, G.W. Stevens, F. Grieser, The optimisation of ultrasonic cleaning procedures for dairy fouled ultrafiltration membranes, Ultrason. Sonochem. 12 (2005) 29-35.

[34] M.L. Xu, X.H. Wen, Z.Y. Yu, Y.S. Li, X. Huang, A hybrid anaerobic membrane bioreactor coupled with online ultrasonic equipment for digestion of waste activated sludge, Bioresour. Technol. 102 (2011) 5617-5625.

[35] M.F.N. Secondes, V. Naddeo, V. Belgiorno, F.B. Jr., Removal of emerging contaminants by simultaneous application of membrane ultrafiltration, activated carbon adsorption, and ultrasound irradiation, J. Hazard. Mater. 264 (2014) 342-349.

[36] M.L. Xu, X.H. Wen, X. Huang, Z.Y. Yu, M. Zhu, Mechanisms of membrane fouling controlled by online ultrasound in an anaerobic membrane bioreactor for digestion of waste activated sludge, J. Membr. Sci. 445 (2013) 119-126.

[37] S.R. Gonzalez-Avila, F. Prabowo, A. Kumar, C.D. Ohl, Improved ultrasonic cleaning of membranes with tandem frequency excitation, J. Membr. Sci. 415-416 (2012) 776-783.

[38] C. Loderer, D. Pawelka, W. Vatier, P. Hasal, W. Fuchs, Dynamic filtrationultrasonic cleaning in a continuous operated filtration process under submerged conditions, Sep. Purif. Technol. 119 (2013) 72-81.

[39] S. Muthukumaran, K. Yang, A. Seuren, S. Kentish, M. Ashokkumar, G.W. Stevens, F. Grieser, The use of ultrasonic cleaning for ultrafiltration membranes in the dairy industry, Sep. Purif. Technol. 39 (2004) 99-107.

[40] T.M. Patel, K. Nath, Alleviation of flux decline in cross flow nanofiltration of two-component dye and salt mixture by low frequency ultrasonic irradiation, Desalination 317 (2013) 132-141.

[41] M. Band, M. Gutman, V. Faerman, E. Korngold, J. Kost, P.J. Plath, V. Gontar Influence of specially modulated ultrasound on the water desalination process with ion-exchange hollow fibers, Desalination 109 (1997) 303-313.

[42] H. Kyllönen, P. Pirkonen, M. Nyström, J. Nuortila-Jokinen, A. Grönroos, Experimental aspects of ultrasonically enhanced cross-flow membrane filtration of industrial wastewater, Ultrason. Sonochem. 13 (2006) 295-302.

[43] C.S. Feng, B.L. Shi, G.M. Li, Y.L. Wu, Preparation and properties of microporous membrane from poly(vinylidene fluoride-co-tetrafluoroethylene) (F2.4) for membrane distillation, J. Membr. Sci. 237 (2004) 15-24.

[44] K. Smolders, A.C.M. Franken, Terminology for membrane distillation, Desalination 72 (1989) 249-262.

[45] Y.B. Yun, R.Y. Ma, W.Z. Zhang, A.G. Fane, J.D. Li, Direct contact membrane distillation mechanism for high concentration $\mathrm{NaCl}$ solutions, Desalination 188 (2006) 251-262.

[46] C. Zhu, G.L. Liu, Modeling of ultrasonic enhancement on membrane distillation, J. Membr. Sci. 176 (2000) 31-41 